\title{
Disability and severe depression among Peruvian older adults: analysis of the Peru Demographic and Family Health Survey, ENDES 2017
}

Joshuan J. Barboza', Anderson N. Soriano-Moreno², Anthony Copez-Lonzoy ${ }^{3,4}$, Josmel Pacheco-Mendoza ${ }^{3}$ and Carlos J. Toro-Huamanchumo ${ }^{5^{*}}$ (i)

\begin{abstract}
Background: Depression is considered a mental health-related disability that affects approximately 350 million people worldwide. On the other hand, it is estimated that 15\% of the world's population lives with some form of disability, and this scenario is currently riddled with the global burden of mental disorders, non-communicable diseases and other age-related comorbidities.

Aim: To assess the association between disability and depression among Peruvian older adults.

Methods: We used data from the 2017 Peru Demographic and Familiar Health Survey, with a focus on adults aged 50 years and older. Whereas the presence of disability was assessed using different questions of the survey, depression was measured with the Patient Health Questionnaire-9 (PHQ-9). We calculated the adjusted prevalence ratios (aPR) using Poisson regression models with log link function, with their respective 95\% confidence intervals (95\% Cl).
\end{abstract}

Results: From the study population, 5\% had a disability. In addition, $43.3 \%$ were screened positive for depression (13.2\% for moderately severe/severe). After adjusting for confounding variables, disability was associated with moderate and severe depression (aPR: 1.06; 95\% Cl: 1.01-1.11, aPR: 1.10; 95\% Cl: 1.05-1.15).

Conclusion: Disability was positively associated with moderate and severe depression. Public health policies should address the early diagnosis and rehabilitation of patients with any of these problems. Likewise, coping strategies should be promoted among families of persons with disabilities.

Keywords: Disabled persons, Depression, Mental health, Surveys and questionnaires, Peru

\footnotetext{
*Correspondence: toro2993@hotmail.com

${ }^{5}$ Universidad San Ignacio de Loyola, Unidad de Investigación para la

Generación y Síntesis de Evidencias en Salud, Av. La Fontana 750, La Molina, Lima, Peru

Full list of author information is available at the end of the article
}

(c) The Author(s). 2020 Open Access This article is licensed under a Creative Commons Attribution 4.0 International License, which permits use, sharing, adaptation, distribution and reproduction in any medium or format, as long as you give appropriate credit to the original author(s) and the source, provide a link to the Creative Commons licence, and indicate if changes were made. The images or other third party material in this article are included in the article's Creative Commons licence, unless indicated otherwise in a credit line to the material. If material is not included in the article's Creative Commons licence and your intended use is not permitted by statutory regulation or exceeds the permitted use, you will need to obtain permission directly from the copyright holder. To view a copy of this licence, visit http://creativecommons.org/licenses/by/4.0/ The Creative Commons Public Domain Dedication waiver (http://creativecommons.org/publicdomain/zero/1.0/) applies to the data made available in this article, unless otherwise stated in a credit line to the data. 


\section{Background}

Depression is considered a mental health-related disability that affects approximately 350 million people worldwide [1], causing high healthcare costs due to the recurrence and chronicity of depressive symptoms (DS) $[2,3]$. Despite efforts for screening and early interventions, the etiology of depression is still not fully understood [4]. Furthermore, the negative impact of DS on the development and worsening of some noncommunicable diseases (NCDs) [5-7] and substance use disorders $[8,9]$ makes even more difficult the understanding of the already complex pathophysiology.

On the other hand, it is estimated that $15 \%$ of the world's population lives with some form of disability [10], and this scenario is currently riddled with the global burden of mental disorders [11], NCDs [12] and other age-related comorbidities [13]. In addition, people with disabilities usually have to face the loss of role within the family, unemployment, the social and selfstigma of disability and low-quality healthcare [14-18].

Current evidence suggests that there is a close relationship between disability and mental health, which includes an increased risk for depression [1, 19]. However, not only the linked pathophysiology and mechanisms are still not fully understood [4], but there are also several factors (e.g. sociodemographic and clinical) which might act as confounders in this relationship [20,21].

In Peru, the probability of having a disability and the disability-Adjusted Life Year (DALYs) from depressive disorders increase from the age of 50 years onwards [22, 23]. In addition, whereas a previous study found an association between physical disability and depression in a population aged 60 years and over [24], other population-based studies only focused on mental health and its comorbidities in general $[25,26]$. Thus, this study aimed to assess the association between disability and depression among Peruvian adults aged 50 years and older, using the Demographic and Family Health Survey (ENDES 2017).

\section{Methods}

\section{Source of information}

The data used in this research was collected during the 2017 Peru Demographic and Familiar Health Survey (ENDES) [27]. The ENDES is a nationally representative, stratified, cluster sample survey performed annually by the National Institute of Statistics and Informatics (INEI). It is composed of three questionnaires (household, reproductive-age women and health) and is performed with the aim to update knowledge about health indicators of the Peruvian population [28]. For this study, we used the health questionnaire data set, which was applied to one person per household aged 15 or above and selected by the last-birthday method [29]. Databases and additional information about the ENDES methodology are publicly available on the INEI web page.

\section{Setting and population}

During 2017, 36,595 households were surveyed in ENDES and 34,099 individuals participated in answering the health questionnaire. We restricted our analysis to 8298 adults aged 50 years and older [30, 31]. A total of 37 participants $(<0.1 \%)$ had missing data in our variables of interest; these were removed from analyses and we worked with a final sub-sample of 8261 individuals.

\section{Exposure: disability}

ENDES assessed disability by using six questions which asked if the responder had permanent limitation to move, talk, heard, see, understand or communicate/ interact with other persons. Disability was defined as a positive answer to any of these limitations. Then, it was dichotomized in yes or no.

\section{Outcome: depression}

Depression was assessed using the Patient Health Questionnaire-9 (PHQ-9), which has been previously validated in Peruvian population [32]. The PHQ-9 requires a respondent to report "over the last 2 weeks, how many days have you felt any of the following problems". Nine items were assessed: (i) "Little interest or pleasure in doing things"; (ii) "Feeling down, depressed, or hopeless"; (iii) "Trouble falling or staying asleep, or sleeping too much"; (iv) "Feeling tired or having little energy"; (v) "Poor appetite or overeating"; (vi) "Trouble concentrating on things"; (vii) "Moving or speaking so slowly that other people could have noticed, or the opposite, being so fidgety or restless that you have been moving around a lot more than usual"; (viii) "Thoughts that you would be better off dead or of hurting yourself in some way", (ix) "Feeling bad about yourself or that you are a failure or have let yourself or your family down". The answers of the questions were recoded using a standardized protocol, 0 to 1 day was recoded as ' 0 '; 2 to 6 days was recoded as ' 1 '; 7 to 11 days was recorded as ' 2 '; and 12 to 14 days was recoded as ' 3 '.

The total score was divided into the following categories of increasing severity: 1-4 for no significant depression; 5-9 for mild depression, 10-14 for moderate depression; and $\geq 15$ for moderately severe/severe depression. These categories were chosen based on the Kroenke et al. research that validated the PHQ-9 for depression severity assessment [33]. 


\section{Other variables}

Based on previous literature we included as confounder variables: Sociodemographic characteristics (sex, age, education, income level, geographical region), lifestyle habits (daily smoking, harmful alcohol consumption, body mass index) and two comorbidities (diabetes and hypertension).

\section{Statistical analysis}

ENDES data sets were downloaded and imported to $\mathrm{R}$ v3.5.2. Using the survey package, we specified the complex design using the primary and secondary sample units, weights and strata for each observation. Categorical variables were described using absolute frequencies, and weighted proportions with $95 \%$ confidence intervals $(95 \% \mathrm{CI})$. For assessing the associations between categories of depressive symptom severity (dependent variable) and the presence of disability (explanatory variable), we used a Poisson regression model with log link function and calculated the adjusted prevalence ratios (aPR) with their respective 95\% CI. We performed three separate models for each category of depression severity, using the category "no significant depressive symptoms" as reference.

\section{Results}

\section{General characteristics of the study population}

Table 1 shows the characteristics of the sample of 8261 adults aged 50 and older. Nearly $5 \%$ of respondents had a disability and $27 \%$ were screened positive for depression. Other important variables were hypertension $(21.4 \%)$, diabetes $(8.4 \%)$, daily smoking $(2.2 \%)$, harmful alcohol consumption (0.4\%), overweight (41.3\%) and obesity (26.8\%).

\section{Depression severity in adults with disabilities}

Among people with disabilities, $43.3 \%$ had depression (weighted \%): 19.4, 10.7 and $13.2 \%$ were screened positive for mild, moderate and moderately severe/severe depression, respectively).

\section{Prevalence of depressive symptom severity by characteristics of the study population}

Severe depression was significantly more frequent among women $(p<0.001)$ and respondents from the highlands $(p<0.001)$, considered poor or very poor by their wealth index $(p<0.001)$, with hypertension $(p<$ $0.001)$, with a harmful alcohol consumption $(p=0.010)$, and with a disability $(p<0.001)$. The age group $(p<$ $0.001)$, education level $(p<0.001)$, geographical region $(p<0.001)$ and body mass index (BMI) $(p<0.001)$ were also related to depressive symptom severity (Table 2 ).
Table 1 General characteristics, disability and depression levels of a sub-sample of Peruvian adults, ENDES $2017(n=8261)$

\begin{tabular}{|c|c|c|c|}
\hline Variables & $\mathrm{n}$ & \% svy & IC 95\% \\
\hline \multicolumn{4}{|l|}{ Sex } \\
\hline Male & 3868 & 47.8 & $45.99-49.64$ \\
\hline Female & 4393 & 52.2 & $50.36-54.01$ \\
\hline \multicolumn{4}{|l|}{ Age group } \\
\hline $50-59$ & 3421 & 44.4 & $42.60-46.24$ \\
\hline $60-69$ & 2476 & 29.3 & $27.73-30.91$ \\
\hline$\geq 70$ & 2364 & 26.3 & $24.59-27.94$ \\
\hline \multicolumn{4}{|l|}{ Education level } \\
\hline No one & 1294 & 10.4 & $9.39-11.32$ \\
\hline Primary & 3654 & 36.2 & $34.39-38.07$ \\
\hline Secondary & 1955 & 29.1 & $27.48-30.79$ \\
\hline Superior & 1358 & 24.3 & $22.31-26.23$ \\
\hline \multicolumn{4}{|l|}{ Geographical Region } \\
\hline Lima Metropolitan area & 797 & 36.8 & $33.66-40.03$ \\
\hline Rest of the coastline & 2290 & 25.2 & $22.99-27.32$ \\
\hline Highlands & 3409 & 27.1 & $24.94-29.17$ \\
\hline Jungle & 1765 & 10.9 & $9.76-12.14$ \\
\hline \multicolumn{4}{|l|}{ Wealth index } \\
\hline Very poor & 3127 & 20.4 & $18.97-21.86$ \\
\hline Poor & 1705 & 15.9 & $14.61-17.18$ \\
\hline Medium & 1323 & 18.6 & $17.04-20.11$ \\
\hline High & 1146 & 21.6 & $19.81-23.30$ \\
\hline Very high & 960 & 23.6 & $21.37-25.76$ \\
\hline \multicolumn{4}{|l|}{ Hypertension } \\
\hline No & 6519 & 78.6 & $77.07-80.05$ \\
\hline Yes & 1742 & 21.4 & $19.95-22.93$ \\
\hline \multicolumn{4}{|l|}{ Diabetes Mellitus } \\
\hline No & 7672 & 91.6 & $90.55-92.64$ \\
\hline Yes & 589 & 8.4 & $7.36-9.45$ \\
\hline \multicolumn{4}{|l|}{ Daily smoking } \\
\hline No & 8078 & 97.8 & $97.20-98.34$ \\
\hline Yes & 183 & 2.2 & $1.66-2.80$ \\
\hline \multicolumn{4}{|l|}{ Harmful alcohol consumption } \\
\hline No & 8232 & 99.6 & $99.43-99.84$ \\
\hline Yes & 29 & 0.4 & $0.16-0.57$ \\
\hline \multicolumn{4}{|l|}{ Body mass index (kg/m2) } \\
\hline Underweight $(<18.5)$ & 137 & 1.2 & $0.88-1.51$ \\
\hline Normal weight (18.5-24.9) & 3063 & 30.7 & $29.05-32.33$ \\
\hline Overweight (25-29.9) & 3144 & 41.3 & $39.50-43.07$ \\
\hline Obese $(\geq 30)$ & 1917 & 26.8 & $25.09-28.56$ \\
\hline \multicolumn{4}{|l|}{ Disability } \\
\hline No & 7727 & 97.8 & $97.20-98.34$ \\
\hline Yes & 534 & 5.0 & $4.27-5.77$ \\
\hline \multicolumn{4}{|l|}{ Depressive symptom severity } \\
\hline No significant depressive symptoms & 5609 & 73.0 & $71.49-74.56$ \\
\hline Mild & 1603 & 16.7 & $15.41-17.89$ \\
\hline Moderate & 578 & 6.1 & $5.27-6.90$ \\
\hline Moderately severe/severe & 471 & 4.2 & $3.63-4.85$ \\
\hline
\end{tabular}


Table 2 Depressive symptom severity by characteristics of the study population, ENDES 2017

\begin{tabular}{|c|c|c|c|c|c|}
\hline \multirow[t]{3}{*}{ Variables } & \multicolumn{4}{|c|}{ Depression levels } & \multirow[t]{3}{*}{$p$} \\
\hline & No significant & Mild & Moderate & Severe $^{\mathbf{a}}$ & \\
\hline & $\boldsymbol{n}=5609$ & $\boldsymbol{n}=1603$ & $\boldsymbol{n}=578$ & $\boldsymbol{n}=471$ & \\
\hline Sex & & & & & $<0.001$ \\
\hline Male & $2979(77.0 \%)$ & 575 (14.9\%) & $170(4.40 \%)$ & 144 (3.72\%) & \\
\hline Female & $2630(59.9 \%)$ & $1028(23.4 \%)$ & 408 (9.29\%) & 327 (7.44\%) & \\
\hline Age group & & & & & $<0.001$ \\
\hline $50-59$ & $2434(71.1 \%)$ & $608(17.8 \%)$ & $223(6.52 \%)$ & $156(4.56 \%)$ & \\
\hline $60-69$ & $1716(69.3 \%)$ & 489 (19.7\%) & 157 (6.34\%) & 114 (4.60\%) & \\
\hline$\geq 70$ & $1459(61.7 \%)$ & $506(21.4 \%)$ & $198(8.38 \%)$ & $201(8.50 \%)$ & \\
\hline Education level & & & & & $<0.001$ \\
\hline No one & $662(51.2 \%)$ & $338(26.1 \%)$ & $148(11.4 \%)$ & 146 (11.3\%) & \\
\hline Primary & $2348(64.3 \%)$ & $797(21.8 \%)$ & $267(7.31 \%)$ & $242(6.62 \%)$ & \\
\hline Secondary & $1464(74.9 \%)$ & $320(16.4 \%)$ & $111(5.68 \%)$ & $60(3.07 \%)$ & \\
\hline Superior & $1135(83.6 \%)$ & 148 (10.9\%) & $52(3.83 \%)$ & $23(1.69 \%)$ & \\
\hline Geographical Region & & & & & 0.001 \\
\hline Lima Metropolitan area & $622(78.0 \%)$ & $112(14.1 \%)$ & $46(5.77 \%)$ & $17(2.13 \%)$ & \\
\hline Rest of the coastline & $1759(76.8 \%)$ & $350(15.3 \%)$ & $112(4.89 \%)$ & $69(3.01 \%)$ & \\
\hline Highlands & $1948(57.1 \%)$ & 835 (24.5\%) & $318(9.33 \%)$ & 308 (9.03\%) & \\
\hline Jungle & $1280(72.5 \%)$ & $306(17.3 \%)$ & $102(5.78 \%)$ & $77(4.36 \%)$ & \\
\hline Wealth index & & & & & $<0.001$ \\
\hline Very poor & $1839(58.8 \%)$ & $748(23.9 \%)$ & $284(9.08 \%)$ & $256(8.19 \%)$ & \\
\hline Poor & $1123(65.9 \%)$ & $338(19.8 \%)$ & $131(7.68 \%)$ & $113(6.63 \%)$ & \\
\hline Medium & $956(72.3 \%)$ & $243(18.4 \%)$ & $66(4.99 \%)$ & $58(4.38 \%)$ & \\
\hline High & $875(76.4 \%)$ & $174(15.2 \%)$ & $65(5.67 \%)$ & $32(2.79 \%)$ & \\
\hline Very high & $816(85.0 \%)$ & $100(10.4 \%)$ & $32(3.33 \%)$ & $12(1.25 \%)$ & \\
\hline Hypertension & & & & & $<0.001$ \\
\hline No & $4578(70.2 \%)$ & 1203 (18.5\%) & $421(6.46 \%)$ & 317 (4.86\%) & \\
\hline Yes & $1031(59.2 \%)$ & $400(23.0 \%)$ & 157 (9.01\%) & $154(8.84 \%)$ & \\
\hline Diabetes Mellitus & & & & & 0.136 \\
\hline No & $5233(68.2 \%)$ & $1476(19.2 \%)$ & $534(6.96 \%)$ & 429 (5.59\%) & \\
\hline Yes & $376(63.8 \%)$ & $127(21.6 \%)$ & $44(7.47 \%)$ & $42(7.13 \%)$ & \\
\hline Daily smoking & & & & & 0.002 \\
\hline No & $5463(67.6 \%)$ & 1577 (19.5\%) & $569(7.04 \%)$ & $469(5.81 \%)$ & \\
\hline Yes & $146(79.8 \%)$ & $26(14.2 \%)$ & $9(4.92 \%)$ & $2(1.09 \%)$ & \\
\hline Harmful alcohol consumption & & & & & 0.008 \\
\hline No & $5597(68.0 \%)$ & $1590(19.3 \%)$ & $576(7.00 \%)$ & $469(5.70 \%)$ & \\
\hline Yes & $12(41.4 \%)$ & $13(44.8 \%)$ & $2(6.90 \%)$ & $2(6.90 \%)$ & \\
\hline Body mass index $(\mathrm{kg} / \mathrm{m} 2)$ & & & & & $<0.001$ \\
\hline Underweight $(<18.5)$ & $84(61.3 \%)$ & $21(15.3 \%)$ & $10(7.30 \%)$ & $22(16.1 \%)$ & \\
\hline Normal weight (18.5-24.9) & $1982(64.7 \%)$ & $642(21.0 \%)$ & $215(7.02 \%)$ & 224 (7.31\%) & \\
\hline Overweight (25-29.9) & $2205(70.1 \%)$ & $582(18.5 \%)$ & 218 (6.93\%) & $139(4.42 \%)$ & \\
\hline Obese $(\geq 30)$ & $1338(69.8 \%)$ & $358(18.7 \%)$ & $135(7.04 \%)$ & $86(4.49 \%)$ & \\
\hline Disability & & & & & $<0.001$ \\
\hline No & $5343(69.1 \%)$ & 1483 (19.2\%) & $517(6.69 \%)$ & 384 (4.97\%) & \\
\hline
\end{tabular}


Table 2 Depressive symptom severity by characteristics of the study population, ENDES 2017 (Continued)

\begin{tabular}{cllll}
\hline Variables & Depression levels & & & \multicolumn{1}{c}{$\boldsymbol{p}$} \\
\cline { 2 - 5 } & No significant & Mild & Moderate & Severe $^{\mathbf{a}}$ \\
& $\boldsymbol{n}=5609$ & $\boldsymbol{n}=1603$ & $\boldsymbol{n}=578$ & $\boldsymbol{n}=471$ \\
\hline Yes & $266(49.8 \%)$ & $120(22.5 \%)$ & $61(11.4 \%)$ & $87(16.3 \%)$
\end{tabular}

${ }^{\mathbf{a}}$ Included both moderately severe and severe depression

\section{Association between disability and depressive symptom severity}

Table 3 shows the prevalence ratios after adjusting for sex, age, education, income, BMI, smoking, harmful alcohol consumption, diabetes and hypertension. We found that disability was positively associated with moderate and severe depression (aPR: 1.06; 95\% CI: 1.011.11 and aPR: 1.10 ; 95\% CI: 1.05-1.15, respectively).

\section{Discussion}

\section{Main findings}

We conducted a secondary analysis using data from the 2017 Peru Demographic and Family Health Survey. The overall prevalence of severe depression in the population was $4.2 \%$ and among people with disabilities was $13.2 \%$.

\section{Depression and disability}

Some mechanisms could explain the reciprocal relationship between disability and depression. First, depression itself is a disabling illness [34]. Second, disability is an independent determinant of the severity of depressive symptoms in different health conditions [34, 35]. Third, depression is usually associated with other important comorbidities such as hypertension and diabetes [36], which could result in a complex disabling condition. Fourth, disability could play the role of chronic stressful condition which increases the risk of developing depression [19]. Fifth, disability and depression might share hormonal and metabolic pathways: Depression has been linked with high levels of cortisol [37] but it has been hypothesized that physical exercise could modulate these levels possibly

Table 3 Adjusted prevalence ratios (aPR) for depressive symptom severity, according to disability, ENDES 2017

\begin{tabular}{lllll}
\hline Depressive symptom severity & Disability & $\mathrm{aPR}^{\mathbf{a}, \mathbf{b}}$ & $95 \% \mathrm{Cl}$ & $\boldsymbol{p}$ \\
\hline Mild $^{c}$ & No & Ref & & \\
& Yes & 1.03 & $0.97-1.08$ & 0.376 \\
Moderate $^{c}$ & No & Ref & & \\
& Yes & 1.06 & $1.01-1.11$ & $\mathbf{0 . 0 2 5}$ \\
Moderately severe/severe $^{c}$ & No & Ref & & \\
& Yes & 1.10 & $1.05-1.15$ & $<\mathbf{0 . 0 0 1}$
\end{tabular}

a Prevalence ratio was adjusted for sex, age, education, income, BMl, smoking and harmful alcohol consumption, diabetes and hypertension

${ }^{b}$ PR calculated using Poisson regression with a robust error variance

${ }^{c}$ Reference category = no significant depressive symptoms due to an upregulation of the glucocorticoid receptor [38]. Since physical inactivity is particularly prevalent among adults with disabilities [39], depression could be a reflection and a consequence of this scenario. Sixth, the complex social and family context of disability can increase the severity of depression [40-42].

It was estimated that in 2015 the proportion of the world's population with depression was $4.4 \%$. Prevalence rates vary by age and peak in most adulthood (above $7.5 \%$ in women aged $55-74$ and above $5.5 \%$ in men) [1]. Depression contributes to functional disability in patients with chronic medical conditions and leads to impairment in self-maintenance and instrumental activities of daily living [43]. Unfortunately, the diagnosis can be particularly tricky because of the clinical overlap of several symptoms that may confound the complex clinical picture of this disorder [44], especially among people with disabilities [45, 46].

In Peru, one study that assessed the relationship between depression and disability was conducted by Martina $\mathrm{M}$ et al. [24]. The research team described that people with disabilities and some level of depression represented $12.7 \%$ of the surveyed population. However, several confounding variables were not assessed, and the study population was restricted to people $\geq 60$ years, which limited the extrapolation of the results. A study conducted in Italy by Solaro C et al. (2016) [47] reported that $19 \%$ of the adult population with multiple sclerosis (considered in this context as a disability) had severe depression. The authors attributed this finding to the correlation between brain damage and the frequency of depressive symptoms, more critical than disability per se. Hughes R et al. (2007) found that $75.4 \%$ of US rural women with a physical disability had severe depression [48], a much higher proportion than in our study. However, both of them used the Beck Depression Inventory-II instead of the PHQ-9. Although in our study mild depression was the most prevalent, it is necessary to consider that disability (primarily physical) in adults is often long and permanent. Thus, depression might reach higher levels if psychological and psychosocial interventions are not taken [1].

\section{Public health relevance}

Depression is considered the leading cause of disability worldwide [49]. In Peru, the implementation of mental health care is still an unmet challenge. It is not available 
in several regions, and private health insurance is not required by law to cover such care [50]. In addition, the absence of a community-based care and rehabilitation system forces patients with disability and depression to live and stay all day at their homes. This often results in family issues, attrition of the primary caregiver, and social discrimination for both the individuals and their families [40-42, 50, 51].

In Peru, the Mental Health Law $\left(\mathrm{N}^{\circ} 30,947\right)$ was recently promulgated on April 2019, establishing the legal framework to guarantee access to services, promotion, prevention, treatment and rehabilitation in mental health, as conditions for the full exercise of the right to health and well-being of the individual, the family and the community [52]. This is certainly an important beginning in the process of addressing the burden of mental illness in the country, especially because it includes the adoption of measures to eliminate barriers to access to mental health care in people with disabilities. However, it is necessary to assess the impact and usefulness of this law, and our results could serve as a baseline for future studies.

\section{Strengths and limitations}

This was a population-based study with a representative and multi-stage sampling. In addition, since ENDES is based on DHS methodology, our results could be compared with other surveys either in Peru or other countries. However, some limitations should be highlighted. First, we cannot infer causality in the interpretation of results due to the cross-sectional design of the study. Moreover, in the interpretation of the results reverse causality can not be ruled out. Second, the World Health Organization defines disability as a continuous phenomenon; however, this variable is dichotomized in the ENDES 2017 (yes/no). Third, since this was a secondary analysis we could not include some potential confounding variables such as the family history of depression or other comorbidities different from hypertension and diabetes. Fourth, PHQ-9 is a screening and not a diagnostic tool for depression, which could produce false-positive results; however, we used validated cut-off points for depressive symptoms severity, which should reduce the risk of misclassification.

\section{Conclusion}

This study found that disability was associated with moderate and severe depression. It is essential to prioritize public health policies that address the early diagnosis and rehabilitation of patients with any of these problems. Likewise, coping strategies should be promoted among families of persons with disabilities.

\section{Abbreviations}

ENDES: Encuesta Demográfica y de Salud Familiar (Demographic and Family Health Survey); INEl: Instituto Nacional de Estadística e Informática (National Institute of Statistics and Informatics); PHQ-9: Patient Health Questionnaire-9; BMl: Body mass index; PR: Prevalence ratio; 95\% Cl: 95\% confidence intervals; NCDs: Non-communicable diseases; DS: Depressive symptoms;

DALYs: Disability-Adjusted Life Year; DHS: Demographic and Health Survey

\section{Acknowledgments}

Not applicable.

\section{Authors' contributions}

JJBM, ANSM, ACL, JPM and CJTH conceived the idea and conceptualized the study and design. ANSM and CJTH performed and reviewed the statistical analyses, respectively. All authors drafted the manuscript and approved the final version.

\section{Funding}

This study was self-funded.

\section{Availability of data and materials}

The datasets generated and/or analyzed during the current study are available in the Peruvian National Institute of Statistics and Informatics repository: http://iinei.inei.gob.pe/microdatos/

Ethics approval and consent to participate

Not applicable since this study involved the use of a previously published secondary database that is publicly available.

Consent for publication

Not applicable.

\section{Competing interests}

The authors declare that they have no competing interests.

\section{Author details}

${ }^{1}$ Universidad San Ignacio de Loyola, Unidad de Revisiones Sistemáticas y Meta-análisis, Lima, Peru. ${ }^{2}$ School of Medicine, Universidad Peruana Unión, Lima, Peru. ${ }^{3}$ Universidad San Ignacio de Loyola, Unidad de Investigación en Bibliometría, Lima, Peru. ${ }^{4}$ Asociación Peruana de Profesionales de las Adicciones - APPADIC, Lima, Peru. ${ }^{5}$ Universidad San Ignacio de Loyola, Unidad de Investigación para la Generación y Síntesis de Evidencias en Salud, Av. La Fontana 750, La Molina, Lima, Peru.

Received: 19 August 2019 Accepted: 13 May 2020

Published online: 24 May 2020

\section{References}

1. World Health Organization. Depression and other common mental disorders: Global Health estimates. Geneva: WHO; 2017.

2. Marcus M, Yasamy M, van Ommeren O, Chisholm D, Saxena S. Depression: a global public health concern. Geneva: World Health Organization; 2012.

3. Welch CA, Czerwinski D, Ghimire B, Bertsimas D. Depression and costs of health care. Psychosomatics. 2009;50(4):392-401.

4. Patten SB. Medical models and metaphors for depression. Epidemiol Psychiatr Sci. 2015;24(4):303-8.

5. Li Z, Li Y, Chen L, Chen P, Hu Y. Prevalence of depression in patients with hypertension: a systematic review and meta-analysis. Medicine (Baltimore). 2015;94(31):e1317

6. Jia Z, Li X, Yuan X, Zhang B, Liu Y, Zhao J, et al. Depression is associated with diabetes status of family members: NHANES (1999-2016). J Affect Disord. 2019;249:121-6.

7. World Health Organization. Addressing comorbidity between mental disorders and major noncommunicable diseases. Copenhagen: WHO Regional Office for Europe; 2017.

8. Dierker L, Selya A, Lanza S, Li R, Rose J. Depression and marijuana use disorder symptoms among current marijuana users. Addict Behav. 2018;76: $161-8$.

9. Quello SB, Brady KT, Sonne SC. Mood disorders and substance use disorder: a complex comorbidity. Sci Pract Perspect. 2005;3(1):13-21. 
10. World Health Organization. World report on disability 2011. Geneva: WHO; 2011.

11. Vigo D, Thornicroft G, Atun R. Estimating the true global burden of mental illness. Lancet Psychiatry. 2016;3(2):171-8.

12. Habib SH, Saha S. Burden of non-communicable disease: global overview. Diabetes Metab Syndr Clin Res Rev. 2010;4(1):41-7.

13. Torres JL, Lima-Costa MF, Marmot M, de Oliveira C. Wealth and disability in later life: the English longitudinal study of ageing (ELSA). PLOS One. 2016; 11(11):e0166825

14. Lépine J-P, Briley M. The increasing burden of depression. Neuropsychiatr Dis Treat. 2011;7(Suppl 1):3-7.

15. Shen S-C, Huang K-H, Kung P-T, Chiu L-T, Tsai W-C. Incidence, risk, and associated factors of depression in adults with physical and sensory disabilities: a nationwide population-based study. PLoS One. 2017;12(3): e0175141.

16. Ali A, Hassiotis A, Strydom A, King M. Self stigma in people with intellectual disabilities and courtesy stigma in family carers: a systematic review. Res Dev Disabil. 2012;33(6):2122-40.

17. Buljevac M, Majdak M, Leutar Z. The stigma of disability: Croatian experiences. Disabil Rehabil. 2012;34(9):725-32.

18. Nurmela K, Mattila A, Heikkinen V, Uitti J, Ylinen A, Virtanen P. Identification of depression and screening for work disabilities among long-term unemployed people. Int J Environ Res Public Health. 2018;15(5):909.

19. Noh J-W, Kwon YD, Park J, Oh I-H, Kim J. Relationship between physical disability and depression by gender: a panel regression model. PLoS One. 2016;11(11):e0166238.

20. Penninx BW, Leveille S, Ferrucci L, van Eijk JT, Guralnik JM. Exploring the effect of depression on physical disability: longitudinal evidence from the established populations for epidemiologic studies of the elderly. Am J Public Health. 1999;89(9):1346-52.

21. Feroz-Nainar C. Confounding factors for depression in adults with mild learning disability. Br J Psychiatry J Ment Sci. 2005;187:89.

22. Ministerio de Salud. Análisis de la Situación de la Discapacidad en el Perú 2007. Lima: MINSA; 2007

23. Global Burden of Disease Collaborative Network. Global Burden of Disease Study 2017 (GBD 2017) Results. Seattle: Institute for Health Metrics and Evaluation (IHME); 2018.

24. Martina M, Ara MA, Gutiérrez C, Nolberto V, Piscoya J. Depresión y factores asociados en la población peruana adulta mayor según la ENDES 20142015. An Fac Med. 2017;78(4):393-7.

25. Instituto Especializado de Salud Mental "Honorio Delgado - Hideyo Noguchi". Estudio Epidemiológico Metropolitano de Salud Mental 2002, Informe general. Lima: IESM HD-HN; 2002.

26. Instituto Especializado de Salud Mental "Honorio Delgado - Hideyo Noguchi". Estudio Epidemiológico de Salud Mental en Lima Metropolitana y Callao Replicación 2012, Informe general. Lima: IESM HD-HN; 2013.

27. Instituto Nacional de Estadística e Informática. Perú: Encuesta Demográfica y de Salud Familiar 2017. Lima: INEl; 2017.

28. Instituto Nacional de Estadística e Informática Perú. Ficha técnica: Encuesta demográfica y de salud familiar 2017. Lima: INEl; 2017.

29. Lavrakas PJ. Encyclopedia of survey research methods. Thousand Oaks: SAGE Publications, Inc; 2008.

30. Gerst-Emerson K, Wong R, Michaels-Obregon A, Palloni A. Cross-National differences in disability among elders: transitions in disability in Mexico and the United States. J Gerontol B Psychol Sci Soc Sci. 2015;70(5):759-68.

31. Limburg $H$, Espinoza $R$, Lansingh VC, Silva JC. Functional low vision in adults from Latin America: findings from population-based surveys in 15 countries. Rev Panam Salud Publica. 2015;37(6):371-8.

32. Calderón M, Gálvez-Buccollini JA, Cueva G, Ordoñez C, Bromley C, Fiestas F. Validación de la versión peruana del PHQ-9 para el diagnóstico de depresión. Rev Peru Med Exp Salud Pública. 2012;29:578-9.

33. Kroenke K, Spitzer RL, Williams JB. The PHQ-9: validity of a brief depression severity measure. J Gen Intern Med. 2001;16(9):606-13.

34. Friedman B, Lyness JM, Delavan RL, null CL, WH B. Major depression and disability in older primary care patients with heart failure. J Geriatr Psychiatry Neurol. 2008;21(2):111-22.

35. Gesztelyi G, Bereczki D. Disability is the major determinant of the severity of depressive symptoms in primary headaches but not in low back pain. Cephalalgia Int J Headache. 2005;25(8):598-604.

36. Valladares-Garrido MJ, Soriano-Moreno AN, Rodrigo-Gallardo PK, MoncadaMapelli E, Pacheco-Mendoza J, Toro-Huamanchumo CJ. Depression among
Peruvian adults with hypertension and diabetes: analysis of a nationa survey. Diabetes Metab Syndr. 2020;14(2):141-6.

37. Dienes KA, Hazel NA, Hammen CL. Cortisol secretion in depressed, and atrisk adults. Psychoneuroendocrinology. 2013;38(6):927-40.

38. Beserra AHN, Kameda P, Deslandes AC, Schuch FB, Laks J, de Moraes HS Can physical exercise modulate cortisol level in subjects with depression? A systematic review and meta-analysis. Trends Psychiatry Psychother. 2018; 40(4):360-8.

39. Centers for Disease Control and Prevention (CDC). Physical activity among adults with a disability--United States, 2005. MMWR Morb Mortal Wkly Rep. 2007:56(39):1021-4.

40. Seltzer MM, Floyd F, Song J, Greenberg J, Hong J. Midlife and aging parents of adults with intellectual and developmental disabilities: impacts of lifelong parenting. Am J Intellect Dev Disabil. 2011;116(6):479-99.

41. Lu N, Liu J, Wang F, Lou WWQ. Caring for disabled older adults with musculoskeletal conditions: a transactional model of caregiver burden, coping strategies, and depressive symptoms. Arch Gerontol Geriatr. 2017;69:1-7.

42. Grey JM, Totsika V, Hastings RP. Physical and psychological health of family carers co-residing with an adult relative with an intellectual disability. J Appl Res Intellect Disabil. 2018;31(Suppl 2):191-202.

43. Kiosses DN, Klimstra S, Murphy C, Alexopoulos GS. Executive dysfunction and disability in elderly patients with major depression. Am J Geriatr Psychiatry. 2001;9(3):269-74.

44. Formánek T, Kagström A, Cermakova P, Csémy L, Mladá K, Winkler P. Prevalence of mental disorders and associated disability: results from the crosssectional CZEch mental health study (CZEMS). Eur Psychiatry J. 2019;60:1-6.

45. Maïano C, Coutu S, Tracey D, Bouchard S, Lepage G, Morin AJS, et al. Prevalence of anxiety and depressive disorders among youth with intellectual disabilities: a systematic review and meta-analysis. J Affect Disord. 2018;236:230-42.

46. Bruce ML. Depression and disability in late life: directions for future research. Am J Geriatr Psychiatry. 2001;9(2):102-12.

47. Solaro C, Trabucco E, Signori A, Martinelli V, Radaelli M, Centonze D, et al. Depressive symptoms correlate with disability and disease course in multiple sclerosis patients: an Italian multi-center study using the Beck depression inventory. PLoS One. 2016;11(9):e0160261.

48. Hughes RB, Nosek MA, Robinson-Whelen S. Correlates of depression in rural women with physical disabilities. J Obstet Gynecol Neonatal Nurs. 2007; 36(1):105-14.

49. Friedrich MJ. Depression is the leading cause of disability around the world. JAMA. 2017;317(15):1517.

50. Rondón MB. Salud mental: un problema de salud pública en el Perú. Rev Peru Med Exp Salud Publica. 2006;23(4):237-8.

51. Guerra M, Ferri CP, Sosa AL, Salas A, Gaona C, Gonzales V, et al. Late-life depression in Peru, Mexico and Venezuela: the 10/66 population-based study. Br J Psychiatry. 2009;195(6):510-5.

52. Perú, Congreso de la Republica. Ley 30947: Ley de Salud Mental. Lima: El Peruano; 2019.

\section{Publisher's Note}

Springer Nature remains neutral with regard to jurisdictional claims in published maps and institutional affiliations.

Ready to submit your research? Choose BMC and benefit from:

- fast, convenient online submission

- thorough peer review by experienced researchers in your field

- rapid publication on acceptance

- support for research data, including large and complex data types

- gold Open Access which fosters wider collaboration and increased citations

- maximum visibility for your research: over $100 \mathrm{M}$ website views per year

At $\mathrm{BMC}$, research is always in progress.

Learn more biomedcentral.com/submission 